\title{
WRITTEN TEXT: APPROACHES TO IDENTIFYING IMPLICIT PRAGMATICS
}

\author{
Galina G. Matveeva \\ Don State Technical University, Rostov-on-Don, Russia \\ Irina A. Zyubina \\ Southern Federal University, Rostov-on-Don, Russia
}

\begin{abstract}
The article deals with the results of the study aimed at discovering features of implicit pragmatics in communicative practice, directed at building scientific or publicist texts. The paragraph organization of the texts that are referred to one of the scientific-educational genres (scientific, scientific-and-popular, educative) is reviewed. It is showed how a pragmatic variation associated with a communicative situation type opens ways for a text composition exposure: a unit of a written text can signal about realization of emotive and/or conative strategies of implicit character. The material of the legal texts written by public prosecutors reveals it that implicit effects are caused by extra-linguistic elements of communication: the professional role of the recipient (court or jury), traditions of a judicial trial typical of various cultures (Russian and English) and time periods (the second half of the $19^{\text {th }}$ cent., $20-40 \mathrm{~s}$ of the $20^{\text {th }}$ cent., the beginning of the $21^{\text {st }}$ cent.). The authors focus their analysis on coordination between the length of the paragraph, text genre (scientific, scientific-and-popular, educative), knowledge of the recipients and their keenness to the topic, considering that the writer of the text usually has the text recipient profile in mind (an individual or heterogeneous audience) and can chose either emotive (self-oriented) or conative (recipientoriented) way of impact. It is concluded that an average type of the reader is a heterogeneous one, which causes such characteristics of the text as an advanced level language culture, besides the writer can chose emotional or conative style of information delivery.
\end{abstract}

Key words: pragmalinguistics, written text, genre, impact, speech strategy.

Citation. Matveeva G.G., Zyubina I.A. Written Text: Approaches to Identifying Implicit Pragmatics. Vestnik Volgogradskogo gosudarstvennogo universiteta. Seriya 2, Yazykoznanie [Science Journal of Volgograd State University. Linguistics], 2018, vol. 17, no. 2, pp. 26-32. (in Russian). DOI: https://doi.org/10.15688/jvolsu2.2018.2.3

\section{ПИСЫМЕННЫЙ ТЕКСТ: ПОДХОДЫ К ВЫЯВЛЕНИЮ СКРЫТОЙ ПРАГМАТИКИ}

\section{Галина Григорьевна Матвеева}

Донской государственный технический университет, г. Ростов-на-Дону, Россия

\author{
Ирина Анатольевна Зюбина \\ Южный федеральный университет, г. Ростов-на-Дону, Россия
}

\footnotetext{
Аннотация. Статья продолжает разработку актуальной для коммуникативной практики проблемы создания эффективных, воздействующих текстов. Проведенный прагмалингвистический анализ научных и юридических письменных текстов позволил авторам определить некоторые способы реализации скрытой прагматики. На примере абзацной организации текстов, относящихся к одной из разновидностей письменной научной коммуникации (собственно научной, научно-популярной и учебной), показано, как прагматическая вариативность обеспечивает адресанту возможность выбора речевых единиц в зависимости от условий коммуникативной ситуации, в частности от характера адресата (единичный или ретиальный). Установлено,
} 
что речевое поведение автора текста зависит от вида речевого воздействия: в письменном научном тексте речевые единицы сигнализируют о реализации эмотивных, ориентированных на автора, и конативных, ориентированных на адресата, стратегий скрытого воздействия. На материале юридических текстов, авторами которых являются государственные обвинители, выявлено, что скрытое воздействие обусловлено экстралингвистическими элементами речевого акта: характером адресата (профессиональный суд или присяжные заседатели), традициями ведения судебного процесса, существовавшими в тот или иной исторический период (вторая половина XIX в., 20-40-е гг. XX в. и начало XXI в.), в той или иной лингвокультуре (русской и английской).

Ключевые слова: прагмалингвистика, письменный текст, жанр, воздействие, речевая стратегия.

Цитирование. Матвеева Г. Г., Зюбина И. А. Письменный текст: подходы к выявлению скрытой прагматики // Вестник Волгоградского государственного университета. Серия 2, Языкознание. - 2018. - Т. 17, № 2. C. 26-32. - DOI: https://doi.org/10.15688/jvolsu2.2018.2.3

\section{Введение}

В статье рассматриваются некоторые эмотивные и конативные свойства текста, для выражения которых привычно и неосознаваемо автором выбираются специальные, предназначенные для воздействия на читателя речевые единицы.

Письменный текст занимает в речевом общении значительное место. Являясь знаком, он имеет три стороны: семантическую, синтаксическую, прагматическую, каждая из которых характеризуется своими критериями оценивания. Семантическая сторона оценивается по критерию адекватности содержания текста объективной реальности. Синтаксическая сторона оценивается по критерию правильности построения текста, то есть соответствия этого строения правилам, установленным для данного языка. Прагматическая сторона оценивается по критерию удачности выбора лингвистических, а точнее речевых, единиц для достижения оптимального воздействия на получателя текста.

Задача статьи состоит в том, чтобы описать некоторые особенности выбора речевых единиц, который совершает отправитель письменного текста, в частности охарактеризовать зависимость организации письменного текста от жанра и от ориентации автора на единичного или ретиального (разнообразного) читателя, зависимость речевого поведения автора текста от вида речевого воздействия эмотивного (ориентированного на себя) и конативного (ориентированного на адресата) и от стратегии скрытого воздействия и экстралингвистических факторов.

\section{Зависимость организации} письменного текста от жанра

\section{и ориентации автора на единичного} или ретиального читателя

Зависимость организации текста, обеспечивающей эффективное воздействие на получателя, от жанра и от характера адресата проиллюстрируем на примере письменного научного общения.

Базовый для нашего исследования термин «речевой жанр» мы понимаем, вслед за M.M. Бахтиным, как устойчивые типы высказываний, характерные для каждой сферы использования языка [Бахтин, 1996]. Рассмотрим три сферы использования языка, в которых сформировались три разновидности речевых жанров - собственно научные, научнопопулярные, учебные. Рассмотрим их с позиций абзацной организации. До сих пор абзац и абзацная организация текста трактовалась в стилистическом, литературно-композиционном, структурно-синтаксическом аспектах. Однако еще в 1929 г. В.Н. Волошинов отмечал, что «только изучение форм речевого общения и соответствующих форм целых высказываний может пролить свет на систему абзацев» [Волошинов, 1929, с. 112]. Поэтому целесообразно провести анализ речевой деятельности автора текста по выделению им абзацев в письменном научном общении с учетом свойств конкретного речевого акта. Такими свойствами оказываются сам текст, его отправитель, его получатель, их пресуппозитивные, социальные и психологические черты, а также ситуация создания текста. Поскольку при создании письменного научного текста непосредственная обратная связь 
между автором и читателем отсутствует, автор ориентируется на предполагаемого получателя текста и на его возможные реакции, исходя из предполагаемого им уровня фоновых и профессиональных знаний читателя. Разумеется, точкой отсчета при этом является его собственный уровень фоновых и профессиональных знаний и автор полагается не на конкретные знания читателя, а на определенный уровень знаний социальной группы, потому что язык, как справедливо утверждает В.Н. Волошинов, отражает «устойчивые социальные взаимоотношения общающихся» [Волошинов, 1929, с. 116].

Одно и то же высказывание для восприятия разными читателями, то есть читателями с разными пресуппозитивными свойствами, представляет неодинаковую трудность. Поэтому одно и то же содержание для разных коммуникантов в разных ситуативных условиях может иметь несколько актуализаций. Назовем их прагмалингвистическими вариантами, ориентированными на разных читателей. Такова сущность разных речевых жанров, которые с позиции прагмалингвистики являются прагмалингвистическими вариантами, потому что они создаются для достижения речевого воздействия на разных читателей. Для разных коммуникантов существует оптимальный способ актуализации воздействующего намерения, то есть предпочитаемая автором речевая единица. Хотя объективно она может оказаться и не оптимальной, более того, с точки зрения системы языка все языковые единицы равнозначны, но для коммуникантов они - разнозначимы и разноценны. Поэтому все прагматические варианты актуализации воздействующего намерения могут быть построены синтаксически правильно, семантически адекватно, но с точки зрения прагматики каждая из них будет оптимальной только для определенных условий протекания общения. Проследим прагматическую вариативность, обеспечивающую эффективность речевой деятельности в зависимости от условий ситуации на примере абзацной организации текстов трех разновидностей письменной научной коммуникации.

Разделяя текст на абзацы, автор тем самым актуализирует оптимальную с его точ- ки зрения стратегию обеспечения восприятия содержания текста читателем. Автор интуитивно рассчитывает длину абзаца так, чтобы не утомить читателя: абзац не должен быть ни слишком длинным, ни слишком коротким для данного получателя текста. Выбор объема абзаца осуществляется при учете автором пресуппозитивных свойств читателя. С точки зрения автора, читателей можно разделить на три группы по объему их профессиональных знаний, а также по интересу к теме изложения. Читатели первой группы обладают меньшим, чем у автора, объемом профессиональных знаний, и интерес к теме сообщения у них слабый. Для такого читателя пишутся научно-популярные тексты. Вторая группа читателей обладает меньшим по сравнению с автором объемом профессиональных знаний, но интересуется темой сообщения, потому что она относится к содержанию их специальности. Для таких читателей пишутся учебники. Читатели третьей группы имеют равные с автором знания и интерес к теме текста. На таких читателей ориентируются авторы научных текстов с изложением новых идей в данной области знания.

Цель автора научно-популярного текста состоит в том, чтобы познакомить читателя с некоторыми актуальными проблемами фундаментальных наук. Поскольку такой читатель обладает низким уровнем профессиональных знаний и неустойчивым интересом к ним, то сложная научная информация излагается занимательно и в доступной форме. Абзац такого текста относительно короткий и составляет в среднем семь строк.

Автор учебного текста также ориентирован на читателя с более низким, чем у него, уровнем профессиональных знаний. Однако по сравнению с автором научно-популярного текста он находится в более выгодном положении, так как такой читатель заинтересован в получении именно данных знаний. Поэтому перед автором стоит задача так организовать и систематизировать информацию, чтобы обеспечить усвоение учебного материала по данной специальности. В связи с этим длина абзаца увеличивается по сравнению с длиной абзаца научно-популярного текста и составляет, как показал анализ, в среднем 11,7 строки. 
Автор собственно научного текста ориентируется на читателя профессионально равного уровня, глубоко знающего предмет изложения, интересующегося новыми веяниями, аспектами, интерпретациями, подходами к раскрытию нерешенных научных проблем. В таких работах длина абзаца значительно возрастает по сравнению с абзацами рассмотренных выше текстов и составляет в среднем от 13,2 до 15,6 строк.

Другим важным фактором, влияющим на речевое поведение автора письменного текста, является количество адресатов, к которым обращается отправитель текста. Это может быть один адресат, известный автору, с которым автор вступает в научную полемику. Это может быть группа читателей той же профессиональной принадлежности, что и автор, для них также создается научный текст. Это может быть и так называемый ретиальный коммуникант, про которого автору ничего неизвестно. В таком случае автору приходится ориентироваться на среднестатистического адресата, хорошо знающего, как и автор, языковую систему и обладающего высоким уровнем речевой культуры.

\section{Зависимость речевого поведения автора письменного текста от вида речевого воздействия}

В качестве иллюстрации рассмотрим научный текст. Его автор решает задачу добиться определенного задуманного речевого воздействия на адресата, которое в целом можно определить как изменение смыслового поля, реализующееся в перлокутивном эффекте речевого акта. Поскольку речевое воздействие - это важная категория прагмалингвистики, описание его сущности, несомненно, представляет интерес. Осуществляется речевое воздействие отправителем текста с учетом всех внутренних и внешних компонентов речевого акта. Приемы реализации речевого воздействия разделим на эмотивные и конативные.

Эмотивные приемы отражают речевую деятельность отправителя текста, ориентированную на проявление собственной личности. Попытка показать себя с точки зрения скрытой прагмалингвистики - эмотивно-ори- ентированное речевое воздействие - реализуется при выборе адресантом речевых единиц следующих трех речевых стратегий скрытого воздействия, связанных с отправителем текста:

- участие / неучастие коммуникантов в речевом событии;

- уверенное / неуверенное речевое поведение автора в речевом событии;

- вероятностное оценивание автором речевого события как реального / нереального.

Другая группа объединяет конативнонаправленные речевые стратегии. Выбор речевого материала для актуализации того или иного плана конативно-направленных событий определяется тем, как автор оценивает пресуппозитивные и фоновые знания читателя. Выделяются следующие конативно-ориентированные стратегии, связанные с получателем текста:

- формирование у получателя текста отношения к речевому событию путем оценивания;

- акцентирование автором элементов высказывания;

- удовлетворение / неудовлетворение автором в тексте прагматических ожиданий получателя текста.

Каждая из этих стратегий маркируется в тексте. Рассмотрим стратегию «участие /неучастие коммуникантов в речевом событии». Она актуализируется в тексте в одном из трех планов: личном, социальном, предметном.

Речевыми сигналами личного плана являются: личные местоимения и финитные формы глагола 1 и 2 л. ед. ч., эксклюзивы $\mathrm{Mbl}$, вы и их падежные формы, а также соответствующие им притяжательные местоимения; формы глаголов в страдательном залоге с локальными и темпоральными детерминантами типа здесь и сейчас при невыраженном, но выводимом из контекста агенсе, под которым подразумевается один из участников конкретного речевого события: побудительные эксклюзивные формы глагола -1 л. мн. ч. и 2 л. ед. и мн. ч.; глагольные лексемы, соотносимые с одним из участников реального речевого события типа кажется, представляется, приходится; нерегулярные ситуативно обусловленные зависимые формы и лексемы, 
содержание которых можно интерпретировать как указание на участие автора или собеседника / читателя в данном речевом событии (подробно см.: [Матвеева, 1993]).

Речевыми сигналами социального плана являются: инклюзивное я и $\mathrm{Mbl}$; инклюзивные формы побудительного наклонения; неопределенная форма глагола; глагольная форма 3 л. мн. ч. при невыраженном агенсе (например, нем. man); деперсонализированное употребле-

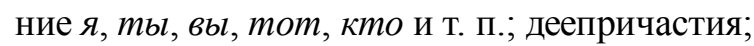
придаточные условные и придаточные образа действия; финитные формы глагола в страдательном залоге с неэксплицированными, но подразумеваемыми коммуникантами; предикативы можно, нужно, нельзя, важно и т. д.; лексемы с семой антропонима типа человечество, народ и др.; нерегулярные ситуативно обусловленные и контекстно зависимые формы и лексемы, которые в конкретном случае можно интерпретировать как указание на совместное участие отправителя и получателя текста в речевом событии.

Набор актуализаторов предметного плана включает в себя те речевые единицы, которые не используются для актуализации первых двух планов, а именно: речевые сигналы наличия действующего лица, к которому нельзя отнести участников речевого события; финитные формы глаголов действительного залога с выраженным или выводимым из контекста или ситуации действующим лицом неучастником речевого события.

\section{Зависимость выбора автором}

\section{речевых единиц от стратегии} скрытого воздействия

\section{и экстралингвистических элементов}

\section{речевого акта}

Неоспоримо наличие сложной социально-биологической природы человека и влияния информации на разные стороны человеческой личности [Матвеева, Зюбина, 2016, c. 64; Матвеева, Зюбина, 2017, с. 107; Стеблецова, 2016, с. 77]. Существуют различные виды социальных и биологических факторов текстовой коммуникации [Ионова, 2011, c. 190]. Чтобы показать зависимость выбора автором речевых единиц от экстралингвистических элементов речевого акта, рассмотрим результаты актуализации некоторых речевых стратегий скрытого воздействия («участие / неучастие коммуникантов в речевом событии», «уверенное / неуверенное речевое поведение автора» и «формирование у получателя текста отношения к речевому событию путем оценивания») на материале юридических текстов - подготовленных (написанных) выступлений русскоязычных и англоязычных государственных обвинителей. Большой объем проанализированного разновременного материала (подробно см.: [Зюбина, 2005]) позволяет представить выявленные зависимости в динамике (вторая половина XIX в., 20-40-е гг. XX в., начало XXI в.) с учетом особенностей адресата - профессиональных судей или присяжных заседателей.

Речевое поведение русскоговорящих государственных обвинителей XXI в., выступавших перед присяжными заседателями, отличается от речевого поведения государственных обвинителей в XIX в. более выраженным стремлением к лидерству и меньшим отрицательным настроем. Выступление русскоговорящих государственных обвинителей перед профессиональным судом в XX в. в отличие от выступлений государственных обвинителей в XXI в. характеризуется более низкой актуализацией личного плана в речевом событии и более высокой актуализацией социального плана скрытой речевой стратегии «участие / неучастие коммуникантов в речевом событии». Современным государственным обвинителям свойственно категоричное речевое поведение и высокий показатель формирования отрицательного отношения к речевому событию. В зависимости от адресата речевое поведение русскоговорящих государственных обвинителей в XXI в., выступавших перед профессиональным судом, отличается более частой актуализацией личного участия в речевом событии, практически полным отсутствием кооперативного поведения, высоким показателем категорического утверждения и высоким формированием отрицательного отношения к речевому событию по сравнению с выступлениями того же периода, но перед судом присяжных заседателей.

Речевое поведение англоговорящих государственных обвинителей в XXI в., выступавших перед судом присяжных заседателей, 
отличается меньшей актуализацией личного участия в речевом событии, значительно более низким показателем уверенного речевого поведения и меньшим обвинительным уклоном, чем у такой же группы русскоговорящих государственных обвинителей.

\section{Выводы}

Анализ элементов письменного текста, отражающих процесс его порождения, позволил обозначить некоторые подходы к выявлению скрытой прагматики.

Прагматическая вариативность обеспечивает адресанту возможность выбора речевых единиц в зависимости от условий коммуникативной ситуации, что проявляется, в частности, в абзацной организации текстов, относящихся к одной из трех разновидностей письменной научной коммуникации. С позиции автора читатели делятся на три группы в зависимости от объема профессиональных знаний и интереса к теме изложения, а длина абзаца, обеспечивающая эффективность восприятия текста читателем и интуитивно рассчитанная автором, обусловлена этими показателями.

Речевое поведение автора письменного текста зависит от вида речевого воздействия (эмотивного или конативного). В научном письменном тексте речевые единицы сигнализируют о реализации эмотивных стратегий скрытого воздействия, связанных с адресантом («участие / неучастие коммуникантов в речевом событии», «уверенное / неуверенное речевое поведение автора в речевом событии», «вероятностное оценивание автором речевого события как реального / нереального») и конативных стратегий скрытого воздействия, связанных с адресатом («формирование у получателя отношения к речевому событию», «акцентирование автором элементов высказывания», «удовлетворение / неудовлетворение автором в тексте прагматических ожиданий получателя текста»).

Выбор речевых единиц для скрытого воздействия обусловлен не только типом стратегии, но и экстралингвистическими элементами речевого акта. В частности, юридические тексты, авторами которых являются государственные обвинители, обнаруживают различия, обусловленные характером адресата (профессиональный суд или присяжные заседатели), традициями ведения судебного процесса, существовавшими в тот или иной исторический период (вторая половина XIX в., 20-40-е гг. XX в. и начало XXI в.), в той или иной лингвокультуре (русской и английской).

Поскольку в науке описаны далеко не все возможные приемы и средства скрытого воздействия текстов на читателя, данная статья продолжает разработку важной в практическом отношении проблемы: как создавать эффективные воздействующие тексты.

\section{СПИСОК ЛИТЕРАТУРЫ}

Бахтин М. М., 1996. Проблема речевых жанров // Собрание сочинений : в 5 т. М. : Русские словари. Т. 5. С. 159-206.

Волошинов В. Н., 1929. Марксизм и философия языка. Л. : Прибой. 188 с.

Зюбина И. А., 2005. Прагмалингвистический аспект речевого поведения русскоговорящего и англоговорящего государственного обвинителя : дис. ... канд. филол. наук. Ростов н/Д. 167 с.

Ионова С. В., 2011. К вопросу о признаках экологичности текстовой коммуникации // Вестник Волгоградского государственного университета. Серия 2, Языкознание. № 1 (13). C. 190-197.

Матвеева Г. Г., 1993. Скрытые грамматические значения и идентификация социального лица («портрета») говорящего : дис. ... д-ра филол. наук. СПб. 322 с.

Матвеева Г. Г., Зюбина И. А., 2016. Речевая привычка как основа речевого портрета говорящего (на материале британского политического дискурса) // Вестник Волгоградского государственного университета. Серия 2, Языкознание. Т. 15, № 4. С. 63-68. DOI: https:// doi.org/10.15688/jvolsu2.2016.4.6.

Матвеева Г. Г., Зюбина И. А., 2017. Речевое поведение авторов исходного и переводного текстов: прагмалингвистический аспект // Вестник Волгоградского государственного университета. Серия 2, Языкознание. Т. 16, № 3. С. $103-$ 111. DOI: https://doi.org/10.15688/jvolsu2. 2017.3.10.

Стеблецова А. О., 2016. Национальный дискурсивный стиль: англоязычный и русскоязычный деловые дискурсы // Вестник Волгоградского государственного университета. Серия 2 , Языкознание. Т. 15, № 4. С. 76-86. DOI: https:// doi.org/10.15688/jvolsu2.2016.4.8 


\section{REFERENCES}

Bakhtin M.M., 1996. The problem of speech genres. Sobranie sochineniy: $v 5$ t. T. 5. Moscow, Russkie slovari Publ., pp. 159-206.

Voloshinov V.N., 1929. Marxism and the philosophy of language. Leningrad, Priboy Publ. $188 \mathrm{p}$.

Zyubina I.A., 2005. Pragmalinguistic aspect of speech behavior of Russian-speaking and Englishspeaking public prosecutor. PhD Thesis. Rostov-on-Don. $167 \mathrm{p}$.

Ionova S.V., 2011. On the signs textual communication's ecologicity. Vestnik Volgogradskogo gosudarstvennogo universiteta. Seriya 2, Yazykoznanie [Science Journal of Volgograd State University. Linguistics], no. 1 (13), pp. 190-197.

Matveeva G.G., 1993. Implicit grammatical meanings and identification of speaker's social face ('portrait'). PhD Thesis. Saint Petersburg. 322 p. Matveeva G.G., Zyubina I.A., 2016. Speech habit as a basis of speaker's speech portrait (based on
British political discourse). Vestnik Volgogradskogo gosudarstvennogo universiteta. Seriya 2, Yazykoznanie [Science Journal of Volgograd State University. Linguistics], vol. 15, no. 4, pp. 63-68. DOI: https://doi.org/ 10.15688/jvolsu2.2016.4.6

Matveeva G.G., Zyubina I.A., 2017. Speech behaviour of original and translated texts' authors: pragmalinguistic aspect. Vestnik Volgogradskogo gosudarstvennogo universiteta. Seriya 2, Yazykoznanie [Science Journal of Volgograd State University. Linguistics], vol. 16, no. 3, pp. 103-111. DOI: https://doi.org/10.15688/ jvolsu2.2017.3.10

Stebletsova A.O., 2016. National discourse style: English and Russian business discourses]. Vestnik Volgogradskogo gosudarstvennogo universiteta. Seriya 2, Yazykoznanie [Science Journal of Volgograd State University. Linguistics], vol. 15 , no. 4 , pp. $76-86$. DOI: https://doi.org/ $10.15688 /$ jvolsu2.2016.4.8

\section{Information about the Authors}

Galina G. Matveeva, Doctor of Sciences (Philology), Professor, Department of World Languages and Cultures, Don State Technical University, Gagarina Sq., 1, 344000 Rostov-on-Don, Russia, gegemat2337633@rambler.ru, https://orcid.org/0000-0002-6407-4274

Irina A. Zyubina, Candidate of Sciences (Philology), Associate Professor, Department of Linguistics and Professional Communication, Southern Federal University, Bolshaya Sadovaya St., 33, 344082 Rostovon-Don, Russia, iazyubina@sfedu.ru,irinazyubina@gmail.com, https://orcid.org/0000-0002-1265-8366

\section{Информация об авторах}

Галина Григорьевна Матвеева, доктор филологических наук, профессор кафедры мировых языков и культур, Донской государственный технический университет, пл. Гагарина, 1, 344000 г. Ростов-на-Дону, Россия, gegemat2337633@rambler.ru, https://orcid.org/0000-0002-6407-4274

Ирина Анатольевна Зюбина, кандидат филологических наук, доцент кафедры лингвистики и профессиональной коммуникации, Южный федеральный университет, ул. Большая Садовая, 33, 344082 г. Ростов-на-Дону, Россия, iazyubina@sfedu.ru, irinazyubina@gmail.com, https://orcid.org/00000002-1265-8366 